\title{
INFLUENCE OF CONTOUR RADIUS AND FIBER ORIENTATION ON HEAT ACCUMULATION DURING MACHINING OF UNIDIRECTIONAL CFRP
}

\author{
J. Mehnen ${ }^{1, *}$, W. Hintze ${ }^{1}$, M. Koeppe ${ }^{1}$ \\ ${ }^{1}$ Hamburg University of Technology, Institute of Production Management and Technology, Hamburg, Germany \\ ${ }^{\star}$ Corresponding author; e-mail: jan.mehnen@tuhh.de
}

\begin{abstract}
The production of carbon fiber reinforced plastic (CFRP) parts requires edge trimming after primary shaping. Heat accumulates in convex workpiece sections, leading to increased temperatures compared to straight edges, possibly compromising the material.

Existing analytical models assume constant thermal conditions and are therefore unable to calculate temperature fields of curved workpiece contours. Accordingly, a numerical simulation for straight contours was extended to convex geometry sections with different radii.

The paper outlines this temperature simulation and presents results for various radii and fiber orientations when machining unidirectional CFRP. Temperature measurements during milling of unidirectional CFRP are used to calibrate the simulation.
\end{abstract}

\section{Keywords:}

CFRP; Unidirectional; Temperature; FEM

\section{INTRODUCTION}

Carbon fiber reinforced plastics (CFRP) are increasingly prevalent in high-performance applications including the aerospace industry. As with other fiber reinforced plastics (FRP), the fiber direction coincides with the highest strength of CFRP parts. Therefore, structural components rely on fiber layups reflecting their load case. Combined with a high specific strength, using CFRP (and FRP) enables weight savings and thus higher fuel efficiency in mobile applications. Consequently, high FRP contents are found in modern aircraft such as Airbus A350 with 53 wt.-\% CFRP [Airbus 2013] and Boeing 787 with 50 wt.-\% FRP [Boeing 2006].

After the tape lay-up of prepregs, CFRP aerospace parts are cured in autoclaves. As this process only produces near-net shape parts, a trimming step is required to generate the final contour. One of the most common postprocessing operations for trimming is milling [SheikhAhmad 2009].

Since CFRP components have reached most of their added value before the final machining step, high quality and reliability of this process are demanded. Therefore, insights into damages inflicted on the parts during the machining of CFRP are necessary. Mechanical damages in CFRP laminates such as delamination are dependent on the fiber orientation angle (of the top ply), defined in Fig. 1. Among others, this was shown by [Koplev 1983], [Colligan 1992] and [Hintze 2011].

Besides mechanical damages, milling can lead to thermal damages of CFRP in the heat-affected zone (HAZ) due to low thermal resistance of the matrix material. Furthermore, elevated temperatures lead to poor machining quality, as the thermally weakened matrix is not able to sufficiently support the fibers [Wang 2016a]. Knowledge about the amount of heat generated in milling and the fraction of this heat entering the workpiece is thus necessary to assess the HAZ's size. In addition to workpiece damage, high temperature levels in machining CFRP in combination with the fibers' abrasiveness accelerate tool wear [Rawat 2009]. Numerous previous works on heat partition with quasiisotropic laminates can be found in the literature. [SheikhAhmad 2020] has conducted experiments on CFRP (plainweave) and GFRP (twill-weave). Here, the heat partition problem was numerically approached with the inverse heat conduction method and showed a ratio of heat to the workpiece of smaller than $14 \%$ for CFRP and smaller than $7 \%$ for GFRP.

However, FRP made of woven fabric are not ideal in terms of mechanical properties as undulations weaken the laminates strength. In addition, fiber volume contents of woven fabrics usually reach no more than $35-50 \%$ in comparison to unidirectional (UD) layers with up to $70 \%$ [Schürmann 2007].

Use of pure UD laminates on the other hand is rare as they are only suitable for single axis loads in fiber direction. Shear loads and loads perpendicular to the fiber direction are taken up by the matrix, leading to a high risk of interfiber fracture [Schürmann 2007]. Therefore, multi-directional CFRP laminates (see Fig. 1) are most commonly used. 


\section{(C) HSM \\ 2021 \\ MM Science Journal | www.mmscience.eu \\ ISSN 1803-1269 (Print) | ISSN 1805-0476 (Online) \\ Special Issue | HSM 2021 \\ $16^{\text {th }}$ International Conference on High Speed Machining \\ October 26-27, 2021, Darmstadt, Germany}

DOI: 10.17973/MMSJ.2021_11_2021156
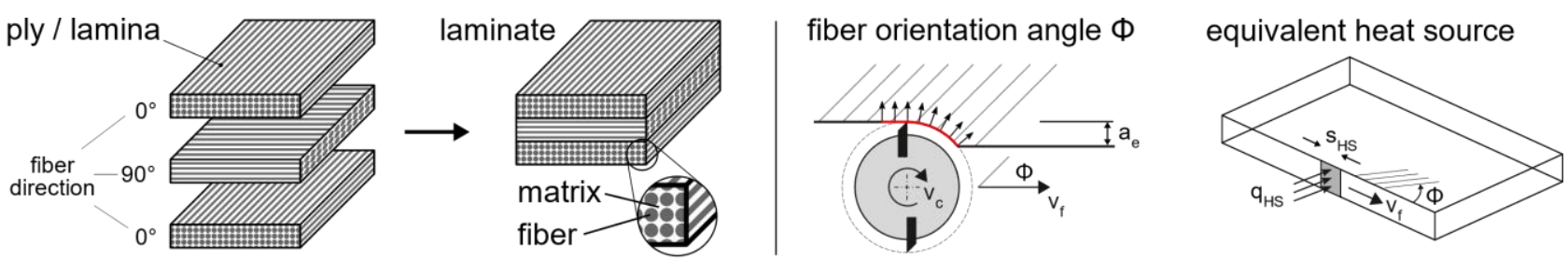

Fig. 1: Multi-directional laminated composite with definition of fiber layup direction (left); heat generating milling process with definition of fiber orientation angle and equivalent heat source (right)

Nevertheless, research on UD material is worthwhile, as experiments on forces in milling of CFRP have demonstrated. In [Wang 1995a], forces of UD laminates were recorded and then, in [Wang 1995b], compared to forces of a multi-directional laminate. It was apparent that forces in the multi-directional laminate may be calculated from the UD laminate forces using superposition and considering the laminate's fiber orientations.

Research on heat partition in milling of UD-CFRP has previously been conducted by [Mehnen 2019] and has shown that heat partition ratios to the workpiece are dependent on the fiber orientation $\Phi$ by using an inverse heat partition model based on a novel analytical approach for orthotropic heat conduction. The heat partition ratios to the workpiece were $20.8 \%\left(\Phi=45^{\circ}\right), 20.6 \%\left(\Phi=90^{\circ}\right)$ and $13.3 \%\left(\Phi=135^{\circ}\right)$. This corresponds to better conduction in fiber direction [Wang 2016b] as the fiber orientation determines the "optimal heat dissipation region" from the contact zone of tool and workpiece into the workpiece.

It is known that heat accumulates in tool-workpiece disengagement regions, such as the cut out region in metal grinding processes, as shown by [Guo 1995]. There, temperatures might surpass those of the steady state due to heat accumulation as there is not material in front of the tool to dissipate the heat further. In case of CFRP, trimming requires the production of convex and concave sections in a workpiece, whereas concave sections do not suffer from heat accumulation. For convex sections, however, heat accumulation is exacerbated by additional heat being introduced from the side, as shown in Fig. 2.

As analytical models are unknown to cover moving heat sources along a curved path of an orthotropic workpiece, such as in trimming of UD-CFRP, this paper outlines temperature simulations for convex workpiece sections and presents results for various radii and fiber orientations. Temperature measurements during milling of UD-CFRP are used to calibrate the simulation. Properties of the equivalent heat source (see Fig. 1) are taken from [Mehnen 2019].

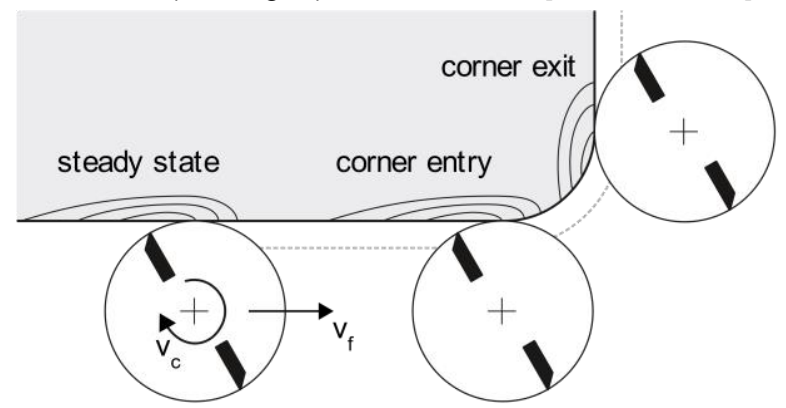

Fig. 2: Situation at convex geometry section of workpiece.

\section{THEORETICAL BACKGROUND}

In the contact zone of tool and workpiece, the mechanical power of milling is mostly converted to heat. Besides the heat flow to the workpiece $\dot{Q}_{w}$ (see Fig. 1) and to the tool $\dot{Q}_{t}$, heat leaves the contact zone via the heat flow in removed hot chips $\dot{Q}_{c}$ and the heat flow from radiation and convection to the environment $\dot{Q}_{e}$. The total heat flow from the contact zone in milling $\dot{Q}_{m}$ is thus divided as follows:

$\dot{Q}_{m}=\dot{Q}_{w}+\dot{Q}_{t}+\dot{Q}_{c}+\dot{Q}_{e}$

As the cutting zone is blocked by tool and workpiece, direct temperature measurements of the cutting zone and derived estimates of heat partition are difficult to realize. In addition, temperature gradients in the workpiece are steep so that measurements close to the cutting zone will not yield accurate results. For CFRP, [Yashiro 2013] and [Wang 2016a] used the tool-workpiece thermocouple method for temperature measurements of the cutting point. [SheikhAhmad 2020] used numerical methods to estimate heat partition and the workpiece temperature field based on thermocouple measurements in the workpiece. In metal cutting, analytical approaches by [Jaeger 1942] and [Carslaw 1959] have been used to describe the workpiece temperature fields, as presented e. g. in [Tönshoff 1992].

In those models, the heat flow to the workpiece is usually regarded as the product of a constant heat flux $q_{H S}$ and a two-dimensional area moving along the workpiece $A_{H S}$ :

$\dot{Q}_{w}=q_{H S} \cdot A_{H S}=q_{H S} \cdot s_{H S} \cdot t$

Here, the product of thermal contact length $s_{H S}$ and the workpiece thickness $t$ represents the heated area $A_{H S}$. The problem is often considered to be two-dimensional as shown in Fig. 3. Furthermore, several other simplifications are made to handle the problem. A two-dimensional constant heat source model as shown in Fig. 3 assumes:

- no mechanical interactions of workpiece and tool;

- no chip removal;

- an adiabatic workpiece apart from the flux through the strip-shaped heat source, thus no heat flow out of the workpiece by radiation or convection;

- a semi-infinite solid instead of a finite volume;

- a constant mean heat flux instead of a realistically periodic heat flux;

- constant material properties that are temperature independent;

- a perfectly orthotropic (or for metals isotropic) material and neglecting the influence of single fibers or fibermatrix transitions on the heat flow; 


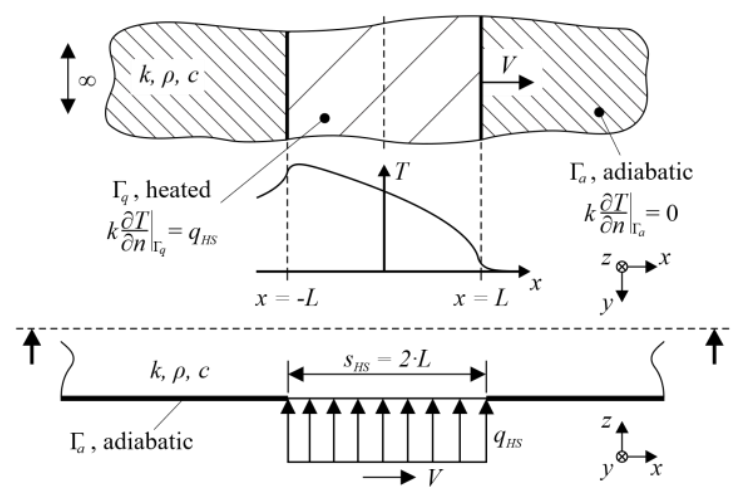

Fig. 3: Two-dimensional model of a strip-shaped heat source moving along a semi-infinite solid [Mehnen 2019].

The models of moving heat sources in [Jaeger 1942] and others derived from it are based on Green's functions which in turn build on the partial differential equation of heat. For the case of orthotropic solids as in [Mehnen 2019], the partial differential equation of heat in Eq. 3 is used.

$k_{11} \frac{\partial^{2} T}{\partial x^{2}}+k_{22} \frac{\partial^{2} T}{\partial y^{2}}+k_{33} \frac{\partial^{2} T}{\partial z^{2}}=\rho c \frac{\partial T}{\partial t}$

For model derivation, see [Carslaw 1959].

\section{SIMULATION SETUP}

In modeling the machining of convex contours in orthotropic material, the same assumptions are made for the numerical simulation as in the analytical model. For initial validation, a simulation was set up in ABAQUS/Standard in combination with the user-subroutine DFLUX for the implementation of a moving heat source. This initial simulation featured a straight edge and was compared to the analytica formulation derived in [Mehnen 2019]. After optimization of minimum mesh sizes and time steps, the temperature change due to the heat source was found to deviate from the analytical model by less than $1 \%$.

Next, the simulation was adapted to model a workpiece geometry of $80 \mathrm{~mm} \times 50 \mathrm{~mm}$ with a radius on one corner, see Fig. 4. Here, a biased seeding down to $0.1 \mathrm{~mm}$ was used to increase accuracy in the curved section. Radii of $\mathrm{R}=5,10$ and $20 \mathrm{~mm}$ were modeled, leading to mesh sizes of $19972(R=5 \mathrm{~mm}), 25396(R=10 \mathrm{~mm})$ and 40352 nodes $(R=20 \mathrm{~mm})$ of type DC3D6 (6-node linear heat transfer triangular prism). Time step size was chosen as $0.05 \mathrm{~s}$.

To implement the heat source, DFLUX subroutine was adapted to the modeled workpiece with curved section. A distinction was made between horizontal, radial and vertical sections, see Fig. 5. Also, transition areas were modeled separately so that no sudden change of thermal contact length and heat flux takes place. Further, a local fiber orientation angle $\Phi_{\mathrm{L}}$ was defined to incorporate the continuously changing fiber orientation in the radial section.

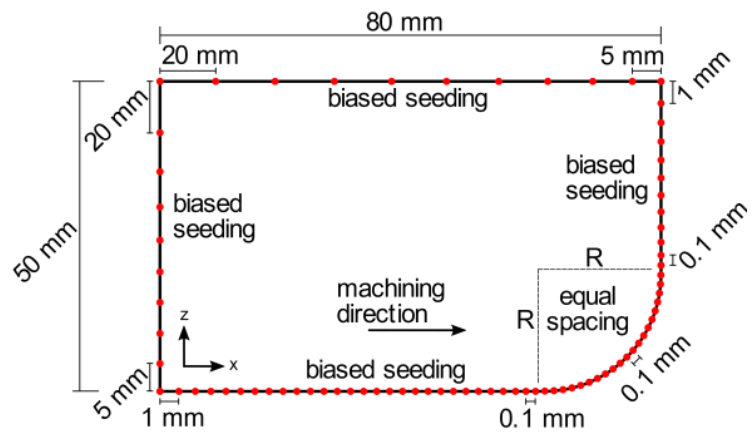

Fig. 4: Simulation setup with mesh seeding (not to scale).

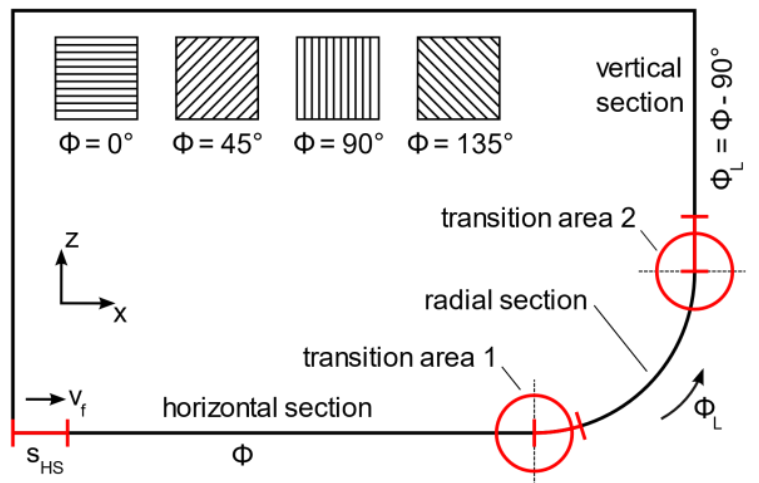

Fig. 5: Division of modeled workpiece into differently handled sections and used fiber orientations $\Phi$ and $\Phi_{\mathrm{L}}$.

Properties of the heat source were taken from [Mehnen 2019]. There, values for $\Phi=0^{\circ}$ (which is the same as $\Phi=$ $180^{\circ}$ ) were not included due to workpiece splitting along the feed direction in experiments for this fiber orientation. Therefore, experiments were repeated for this paper. To prevent workpiece splitting, glass fabric laminates were bonded to both sides of the UD-CFRP workpiece as described in section 4 . In addition, to consider the influence of the glass fabric on the spindle power measurements, separate measurements of machining glass fabric laminates were conducted and subtracted. Average mechanical power for $0^{\circ}$ UD-CFRP was determined to be $11.55 \mathrm{~W}$, using the same material, tool and process parameters as in [Mehnen 2019], see also Tab. 1 and Tab. 2.

Using the same algorithm as in [Mehnen 2019] to optimize for thermal contact length $s_{H S}$ and heat flux $q_{H S}$ yielded unreallistically small values for $s_{H S}$ in the range of $0.04 \mu \mathrm{m}$. However, as the error, for which the optimiziation algorithm searched the minimum value, did not change significantly up to a value of $s_{H S}=1.0 \mathrm{~mm}$, this value was chosen for $\Phi=0^{\circ}$. The resulting heat flux was calculated to be $q_{H S}=332.9 \mathrm{~kW} / \mathrm{m}^{2}$, leading to a heat source power of $\mathrm{P}_{\text {HS }}=1.33 \mathrm{~W}$ which corresponds to $11.5 \%$ of the mechanical power in this process. The maximum surface temperature change follows with $\Delta T_{s, \max }=158.68 \mathrm{~K}$.

All heat source properties are also displayed in Fig. 6 . In the radial section, linear interpolation was used to accomodate for the continously changing local fiber orientation angle $\Phi_{\mathrm{L}}$. This leads to the implementation of the same values as displayed on the connecting lines in Fig. 6.
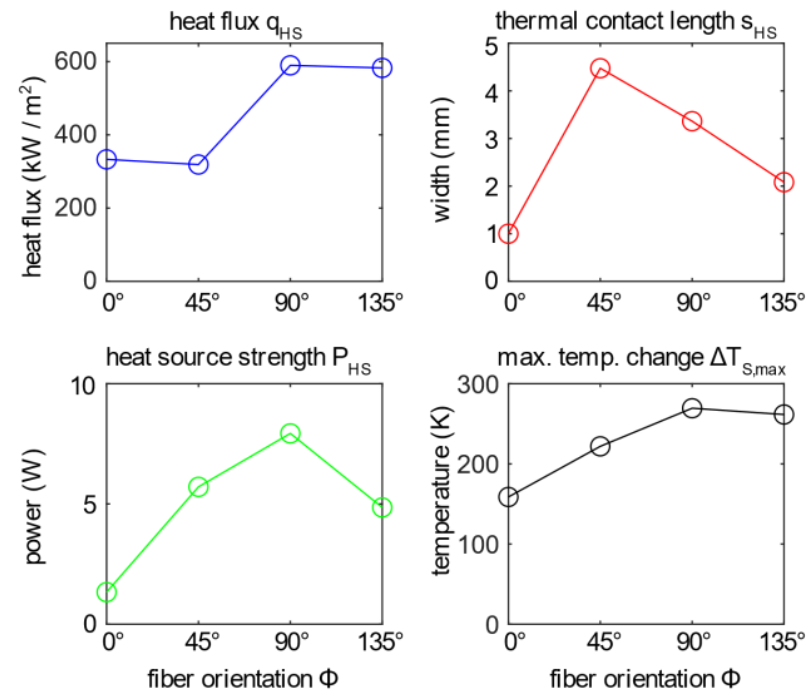

Fig. 6: Heat source properties with values from [Mehnen 2019] and additional values for $\Phi=0^{\circ} / \Phi=180^{\circ}$. 
As the simulation was supposed to follow the same conditions as the experiment, it was necessary to decrease the feed velocity in the radial section to match the present radius. Under consideration of the tool diameter $d_{t}=8 \mathrm{~mm}$, a tool center velocity of $v_{f}=0.002 \mathrm{~m} / \mathrm{s}=0.12 \mathrm{~m} / \mathrm{min}$ leads to velocities of the moving heat source on the circular section of

- $v_{f, 5}=0.067 \mathrm{~m} / \mathrm{min}$ for $\mathrm{R}=5 \mathrm{~mm}$

- $v_{f, 10}=0.086 \mathrm{~m} / \mathrm{min}$ for $\mathrm{R}=10 \mathrm{~mm}$ and

- $v_{f, 20}=0.100 \mathrm{~m} / \mathrm{min}$ for $\mathrm{R}=20 \mathrm{~mm}$.

\section{EXPERIMENTAL METHODS}

For experimental validation of the simulation of heat conduction in convex workpieces with three different radii, matching milling experiments were done using UD-CFRP panels with varying fiber orientation. Workpiece temperatures were measured with thermocouples (TCs).

\subsection{Material}

UD-CFRP made of Cycom 977-2-35-24K IMS 268 prepregs with $268 \mathrm{gsm}$ was used in the milling experiments. The [0] $]_{16}$ layup of $0.25 \mathrm{~mm}$ layers resulted in a panel thickness of $4.0 \mathrm{~mm}$. Tab. 1 lists the CFRP's material properties relevant for thermal conduction which were also used in the corresponding simulations. As UD-CFRP is prone to fracturing perpendicular to its fiber direction, the specimens were strengthened by applying $1 \mathrm{~mm}$ thick glass fabric-based laminates on both sides, which also hindered surface heat loss in the experiments due to its low thermal conductivity. The fabric EP GC 203 (in accordance with EN 60893) with the following properties, see [BK 2006], was used:

- thermal conductivity of $0.25 \mathrm{~W} /(\mathrm{m} \mathrm{K})$;

- density of $1.86 \mathrm{~g} / \mathrm{cm}^{3}$;

- limit temperature of $180^{\circ} \mathrm{C}$.

Bonding of UD-CFRP and glass fabric (both roughened and cleaned) was done with dual-component epoxy adhesive UHU Plus Endfest 300 by hot pressing at $20 \mathrm{kN}$ and $80{ }^{\circ} \mathrm{C}$ for 30 minutes, reaching a bond strength of above $20 \mathrm{MPa}$, see [UHU 2012]. Specimens with a combined area of approximately $400 \mathrm{~cm}^{2}$ were pressed simultaneously. Fig. 7 shows the specimens' cross section with introduced thermocouple. Specimen size was $80 \mathrm{~mm} \times 50 \mathrm{~mm}$, while milling was done on the long side first.

Tab. 1: Material properties of used UD-CFRP.

\begin{tabular}{|c|c|c|c|}
\hline Parameter & Symbol & Value & Unit \\
\hline Density & $\rho$ & 1598 & $\mathrm{~kg} / \mathrm{m}^{3}$ \\
\hline Specific heat & $\mathrm{c}$ & 815.7 & $\mathrm{~J} \mathrm{~kg}^{-1} \mathrm{~K}^{-1}$ \\
\hline $\begin{array}{l}\text { Heat conductivity } \\
\text { parallel to fibers }\end{array}$ & $\mathrm{k}_{11}$ & 6.96 & $\mathrm{~W} \mathrm{~m} \mathrm{~m}^{-1} \mathrm{~K}^{-1}$ \\
\hline $\begin{array}{l}\text { Heat conductivity } \\
\text { perpendicular to fibers }\end{array}$ & $\mathrm{k}_{33}$ & 0.796 & $\mathrm{~W} \mathrm{~m}^{-1} \mathrm{~K}^{-1}$ \\
\hline
\end{tabular}

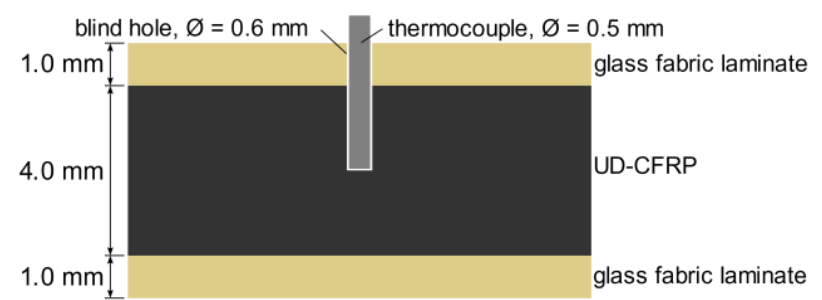

Fig. 7: Cross section of UD-CFRP specimen with glass fabric laminate reinforcement and TC.
Tab. 2: Tool properties and machining parameters.

\begin{tabular}{llll}
\hline Parameter & Symbol & Value & Unit \\
\hline Cutting speed & $\mathrm{v}_{\mathrm{c}}$ & 100 & $\mathrm{~m} / \mathrm{min}$ \\
Feed per tooth & $\mathrm{f}_{\mathrm{z}}$ & 0.015 & $\mathrm{~mm}$ \\
Feed rate & $\mathrm{V}_{\mathrm{f}}$ & 0.002 & $\mathrm{~m} / \mathrm{s}$ \\
Tool engagement & $\mathrm{a}_{\mathrm{e}}$ & 1.5 & $\mathrm{~mm}$ \\
Depth of cut (thickness) & $\mathrm{a}_{\mathrm{p}}$ & 6.0 & $\mathrm{~mm}$ \\
Tool diameter & $\mathrm{d}_{\mathrm{t}}$ & 8.0 & $\mathrm{~mm}$ \\
Clearance angle & $\mathrm{a}_{\mathrm{f}}$ & 12 & $\circ$ \\
Rake angle & $\mathrm{Y}$ & 0 & $\circ$ \\
Helix angle & $\delta$ & 1.6 & $\circ$ \\
\hline
\end{tabular}

\subsection{Tool and cutting parameters}

A two-fluted PCD end mill of Gühring $K G$ was used in a machining center Röders RFM600 of Röders $\mathrm{GmbH}$. For machining, the same tool and the same parameters as in [Mehnen 2019] were used to achieve comparability as well as to implement the findings of heat source width and heat flux in the simulation. Tab. 2 shows geometrical properties of the tool as well as machining parameters.

\subsection{Measurement equipment}

Four TCs of Type-J, tolerance class 1, by $T C \mathrm{GmbH}$ with stainless steel sheaths of $\varnothing 0.5 \mathrm{~mm}$ were used in the experiments. They were inserted into $\varnothing 0.6 \mathrm{~mm}$ blind holes that were previously filled with heat conductive paste, see Fig. 7 and Fig. 9. Besides a low disturbance of the temperature field, the small diameter leads to a small response time of $0.030 \mathrm{~s}$. One TC was placed at the beginning of the convex circle segment, one in the center and one at the end, each with $1.5 \mathrm{~mm}$ offset to the finished edge. One additional TC was placed $3 \mathrm{~mm}$ behind the TC in the circle segment center. Fig. 8 visualizes the TC placement and numbering. Thermocouple installation is shown in Fig. 9.

The TCs were connected to an input module NI 9210 of National Instruments Corp. with a combined sample rate of $14 \mathrm{~Hz}$, leading to a sample rate of $3.5 \mathrm{~Hz}$ for each of the four TCs. For the described process parameters and feed velocities, this leads to temperature measurements taken after every $0.57 \mathrm{~mm}$ of feed movement.

Mechanical process power was recorded by measuring the spindle torque with a rotating dynamometer $9125 \mathrm{~A}$ of Kistler Instrumente $A G$ at a sample rate of $5000 \mathrm{~Hz}$ and multiplying the moving average of the torque by the angular velocity.

For comparing experiment and simulation, temperatures at the experimental TC locations were taken from the simulation.

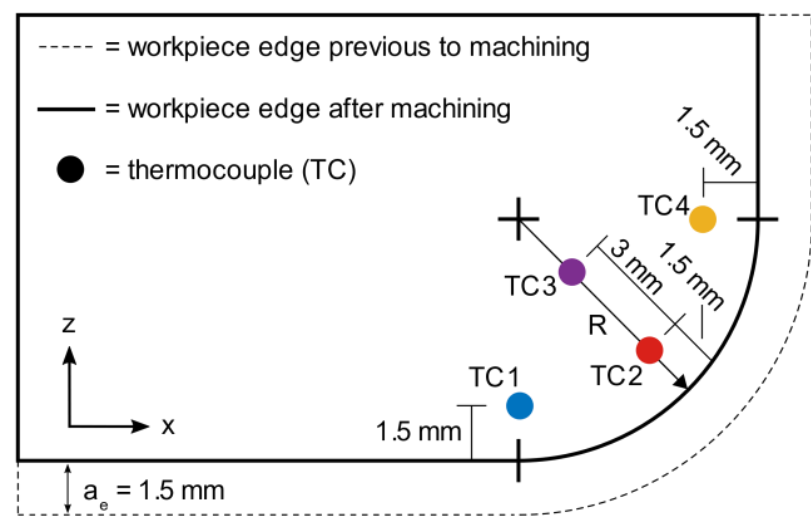

Fig. 8: TC placement and numbering (not to scale). 


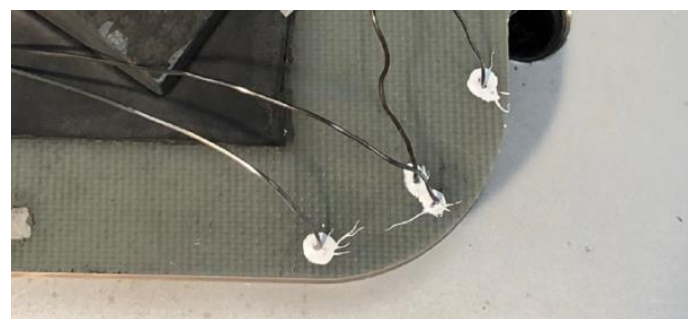

Fig. 9: Thermocouple installation.

\section{RESULTS AND DISCUSSION}

Experiments were conducted according to section 4. When examining temperatures measured by the first thermocouple that receives heat, $\mathrm{TC} 1$, it became apparent that temperature levels were lower than those in [Mehnen 2019], see Fig. 10. This presumably resulted from a shorter initial horizontal cutting path of less than $80 \mathrm{~mm}$ (depending on the radius) instead of feed paths of $200 \mathrm{~mm}$ at the position of the TCs in [Mehnen 2019].

Nevertheless, a correlation is found between maximum temperature levels and radius size, see Fig. 11, as a lower radius generally corresponds to higher temperatures in the experiments (the exception being $\Phi=45^{\circ}$ at $R=10 \mathrm{~mm}$ due to corner chipping). Also, the TC location of maximum temperatures corresponds to the fiber orientation $\Phi$ (equal to $\Phi_{\mathrm{L}}$ of TC1). For $\Phi=0^{\circ}$ and $\Phi=45^{\circ}$, the maximum temperature is always found at the exit of the corner at TC4, while for $\Phi=90^{\circ}$, the entry of the corner at TC1 shows the highest temperatures. For $\Phi=135^{\circ}$, the maximum is either found at the corner entry or in the middle section.

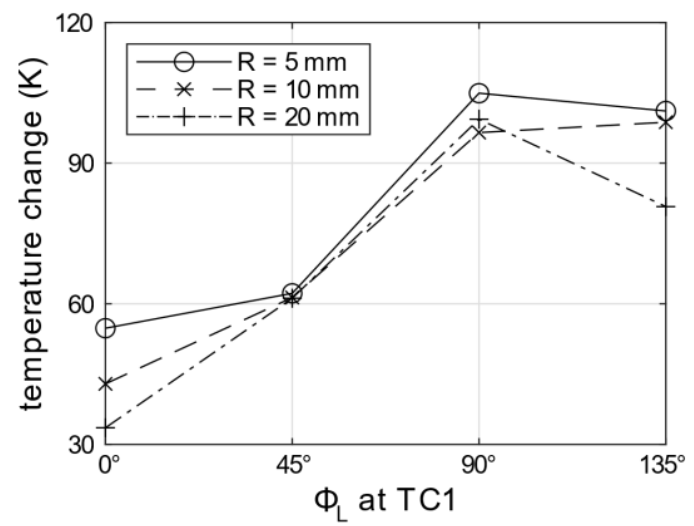

Fig. 10: Maximum measured temperatures of TC1 for different fiber orientations and radii.

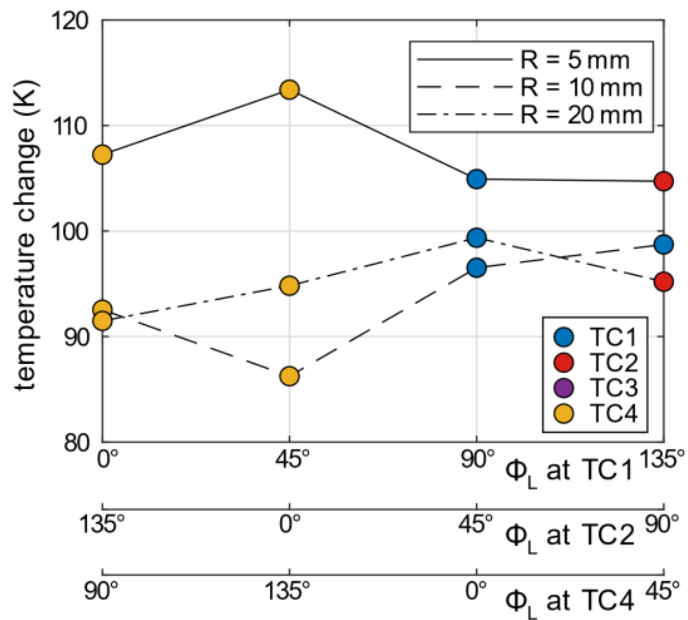

Fig. 11: Maximum measured temperatures of all TCs for different fiber orientations and radii.
Due to the shorter feed path of the tool before reaching the TCs, the temperatures were generally lower in the present experiments compared to the previous experiments of [Mehnen 2019]. To accommodate for this fact, the simulation was adjusted. Therefore, the ratios of maximum temperature levels of TC1 were taken as a correction factor for the heat flux qHS so that the temperatures at the entry of the curved section corresponded to each other. For an unadjusted simulation compared to the experiment see Fig. 12 (top). The first adjustment by TC1-corrected heat flux is shown in Fig. 12 (center). Correction factors varied between 0.43 and 0.68 .

An additional correction factor was taken into account as the thermal contact length $\mathrm{q}_{\mathrm{HS}}$ is reduced by the curvature. The tool itself has less contact to the material and, in addition, heated material in front of the tool is removed that would not be removed in a straight edge situation. Therefore, the ratio of the maximum temperatures of experiment and simulation of TC2 was used in the second correction factor. The result of the correction is shown in Fig. 12 (bottom). Correction factors for all contour radii $\mathrm{R}$ varied between 0.36 and 0.84 for $\Phi=45^{\circ}$ to $\Phi=135^{\circ}$, whereas $\Phi=0^{\circ}$ showed values between 0.78 and 1.05 , indicating a different behavior that could arise from workpiece chipping at the entry of the curvature for this fiber orientation.
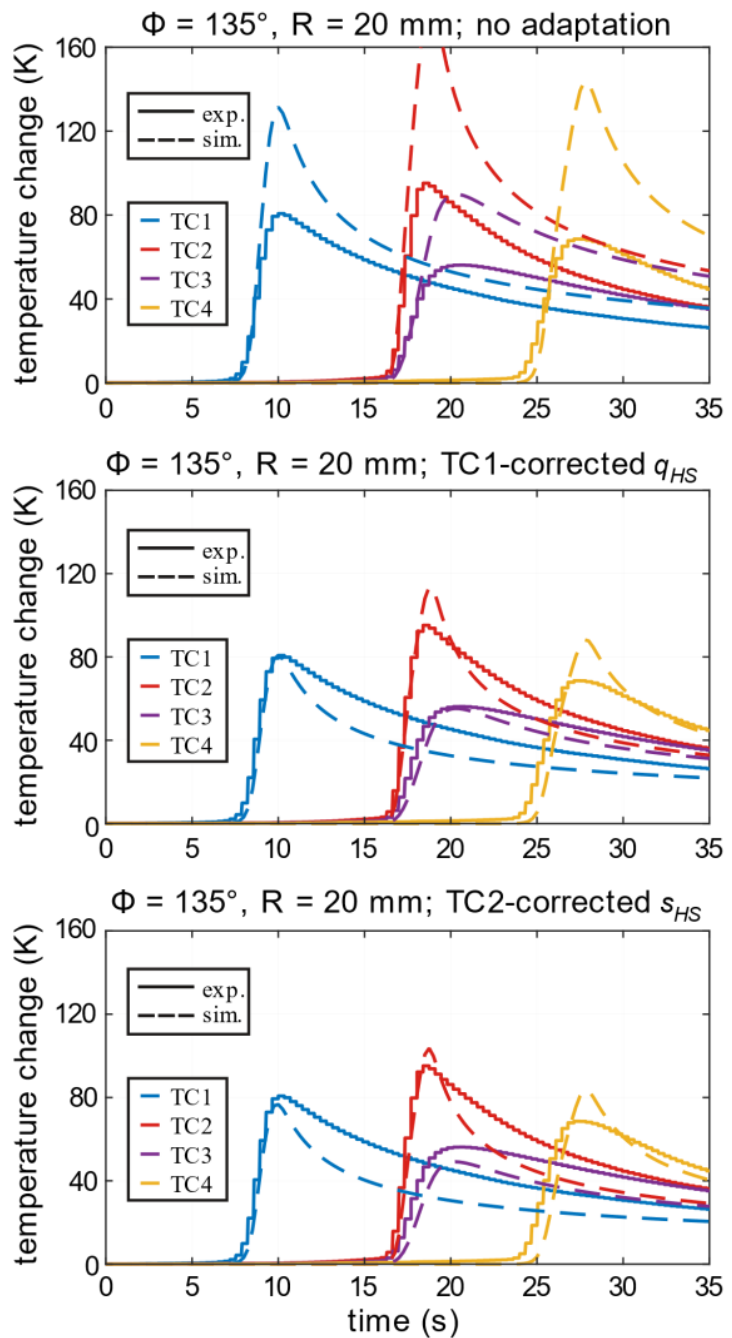

Fig. 12: Comparison of simulation and experiment at $\Phi=135^{\circ}$ and $R=20 \mathrm{~mm}$. Top: Simulation with no adaptation; Center: Simulation with TC1-corrected heat flux; Bottom: Simulation with TC1-corrected heat flux and TC2-corrected thermal contact length 

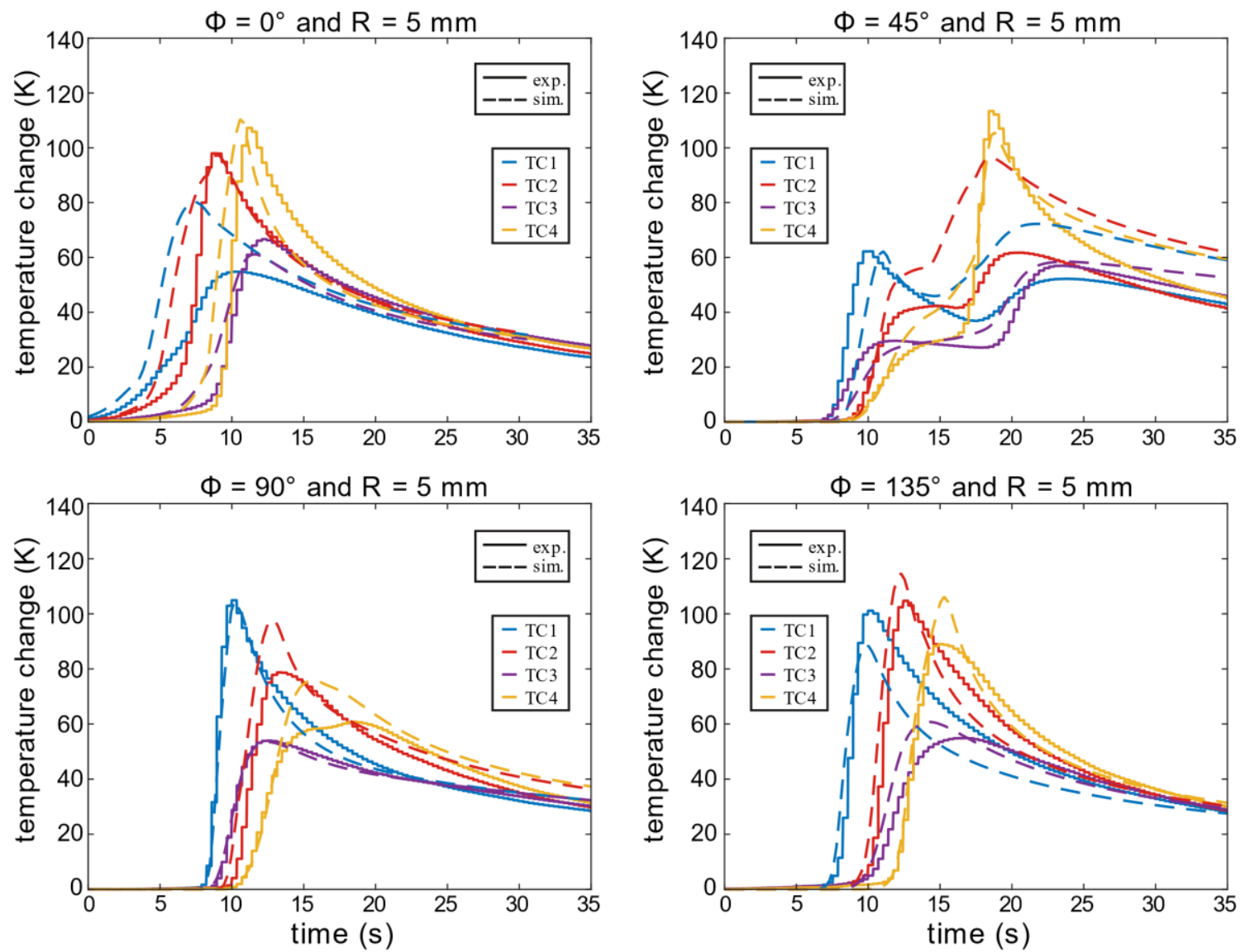

Fig. 13: Comparison of experiment and adapted simulation at $R=5 \mathrm{~mm}$ for every fiber orientation.
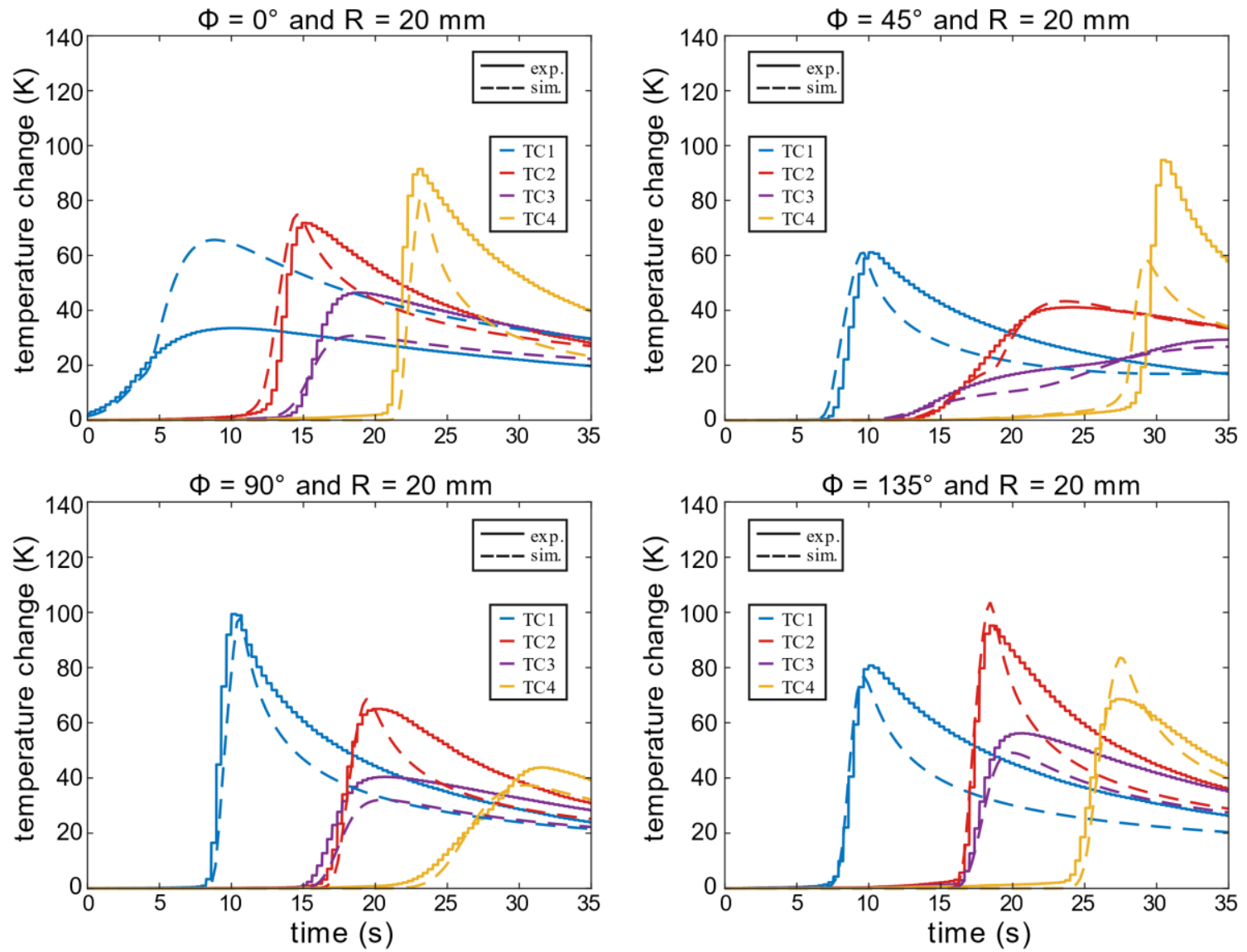

Fig. 14: Comparison of experiment and adapted simulation at $R=20 \mathrm{~mm}$ for every fiber orientation. MM Science Journal | 2021 | NOVEMBER - Special Issue on HSM2021 
For further comparison, graphs of all fiber orientations for $\mathrm{R}=5 \mathrm{~mm}$ and $\mathrm{R}=20 \mathrm{~mm}$ are included in Fig. 13 and Fig. 14, respectively. It is apparent that simulated temperatures show an overall equal behavior as experimental temperatures. There are some notable exceptions, however. For radii $R=5 \mathrm{~mm}$ and $R=20 \mathrm{~mm}$ at $\Phi=0^{\circ}$, TC1 values, which represent the entry to the curved section, are significantly lower in the experiments, presumably due to mentioned workpiece chipping. The same applies to $R=20 \mathrm{~mm}$ and $\Phi=45^{\circ}$, as values of TC2 were exceptionally low in the experiments compared to $\mathrm{R}=5 \mathrm{~mm}$, leading to a distorted correction factor based on the maximum TC2 value. Furthermore, many simulated temperatures show a quicker decline than their experimental counterparts, especially regarding the larger radius $R=20 \mathrm{~mm}$. This could correlate with the glass fabric laminates in the experiment which transmit heat with a time delay due to their lower thermal conductivity. Thus, the temperature of the UD-CFRP is held up by heat transmitted through the glass fabric laminates.

The presented experiments show maximum temperature changes of over $100 \mathrm{~K}$ depending on corner radius $\mathrm{R}$ and fiber orientation $\Phi$. However, due to the relatively cool tool, measured temperature changes in the present research are certainly surpassed when using a tool in steady state temperature condition. This is indicated by the TC1 correction factor, resulting in possibly twice as high temperature changes, depending on initial fiber orientation $\Phi$ and radius $R$.

Especially in case of the smaller contour radii $R=5 \mathrm{~mm}$ and $\mathrm{R}=10 \mathrm{~mm}$ (not pictured), an additional temperature peak behind the first was observed in experiments as well as simulations of $\Phi=45^{\circ}$. This can be assigned to heat fluxes in fiber direction which act forward and backward with respect to the feed direction. This agreement supports the quality of the derived model.

\section{SUMMARY AND OUTLOOK}

In this paper, temperature fields in machining of convex parts of UD-CFRP workpieces were investigated. Milling experiments were conducted with radii of the convex sections of $R=5,10$ and $20 \mathrm{~mm}$ while initial fiber orientations of $\Phi=0^{\circ}, 45^{\circ}, 90^{\circ}$ and $135^{\circ}$ were used.

As no analytical models for orthotropic materials such as UD-CFRP are known that cover moving heat sources along a straight section which transitions into a curved path, corresponding numerical simulations with the same radii and fiber orientations as in the experiments were set up in ABAQUS/Standard.

For the simulation, properties of the equivalent heat source were taken from [Mehnen 2019]. Because of reduced workpiece sizes in the present research, temperatures were lower than in [Mehnen 2019], leading to the introduction of a correction factor based on the first thermocouple TC1 located at the entry of the curved section. A second correction factor was implemented to accommodate for a reduced thermal contact length in the convex part of the workpiece.

The following conclusions could be drawn:

- the location of maximum experimental TC temperatures was strongly dependent on the fiber orientation;

- a smaller radius of the convex contour corresponds to increased maximum temperatures;

- numerical simulations are able to model the behavior of the material when set up with basic heat source properties and adapted to the local situation;
Next, the experiments should be repeated with larger workpieces and a higher number of thermocouples to assess the heating of the tool up to a steady state, making TC1 correction unnecessary.

In addition, a prediction of the second correction factor considering the radius-dependent geometric contact length between tool and curved contour is intended.

The comparison of experimental and simulated temperatures could be further improved by modeling the glass fabric laminate in the simulation, thereby addressing the faster temperature decline in the simulations compared to the experiments.

When developing the simulation to reflect the behavior of multidirectional laminates, combinations of several stacked heat sources with properties from unidirectional research could be used for a thermal superposition.

In addition, the potential damage to the material should be assessed. This results not only from overheating of the matrix material but also possibly from thermally induced internal stresses in the heat affected zone of the laminate.

\section{ACKNOWLEDGMENTS}

The authors would like to cordially thank Guehring KG for the provision of PCD-tools.

\section{REFERENCES}

[Airbus 2013] Airbus SE. Airbus technical magazine FAST: Special Edition A350XWB. 2013

[BK 2006] BK Kunststoffe Bernau GmbH. Glass FabricBased Laminates. Data sheet. 2006

[Boeing 2006] The Boeing Company. AERO: QTR 04. 2006

[Carslaw 1959] Carslaw, H. S. and Jaeger, J. C. Conduction of Heat in Solids. Oxford: Clarendon Press, 2nd ed., 1959.

[Colligan 1992] Colligan, K. and Ramulu, M. The effect of edge trimming on composite surface plies. Manufacturing Review, 1992, Vol. 5, No. 5, pp. 274-283

[Guo 1995] Guo, C. and Malkin, S. Analysis of Transient Temperatures in Grinding. ASME - Journal of Engineering for Industry, 1995, Vol. 117, No. 4, pp. 571-577. https://doi.org/10.1115/1.2803535

[Hintze 2011] Hintze, W. et al. Occurrence and propagation of delamination during the machining of carbon fibre reinforced plastics (CFRPs). Composites Science and Technology, 2011, Vol. 71, No. 15, pp. 1685-1790

[Jaeger 1942] Jaeger, J.C. Moving sources of heat and the temperature at sliding contacts. Journal and Proc. of the Royal Society of N.S.W., 1942, Vol. 76, pp. 203-224

[Joven 2012] Joven, R. et al. Thermal properties of carbon fiber-epoxy composites with different fabric weaves. In: SAMPE International Symposium Proceedings (44th ISTC), Charleston (SC), USA, 22-25 October 2012

[Koplev 1983] Koplev, A. et al. The cutting process, chips, and cutting forces in machining CFRP. Composites, 1983, Vol. 14, No. 4

[Mehnen 2019] Mehnen, J., Hintze, W., et al. Temperature field due to a moving heat source in machining orthotropic composites with arbitrary fiber orientation. In: K. Kerrigan et al., ed. Proceedings of the 2nd CIRP Conference on Composite Material Parts Manufacturing (CCMPM), Sheffield, United Kingdom, 10-11 October 2019, pp. 2-7. https://doi.org/10.1016/j.procir.2019.09.019

[Rawat 2009] Rawat, S. and Attia, H. Wear mechanisms and tool life management of WC-Co drills during dry high 
speed drilling of woven carbon fibre composites. Wear, 2009, Vol. 267, pp. 1022-1030. https://doi.org/10.1016/j.wear.2009.01.031

[Schuermann 2007] Schuermann, H. Konstruieren mit Faser-Kunststoff-Verbunden. Berlin: Springer, 2007. ISBN 978-3-540-72189-5

[Sheikh-Ahmad 2009] Sheikh-Ahmad, J. Y. Machining of Polymer Composites. Boston, MA. Springer US. 2009.

[Sheikh-Ahmad 2020] Sheikh-Ahmad, J. Y., et al. Heat partition in edge trimming of fiber reinforced polymer composites. J. of Comp. Mat., 2020, Vol. 54, No. 21, pp. 2805-2821. https://doi.org/10.1177/0021998320904129

[Toenshoff 1992] Toenshoff, H. K. et al. Modelling and simulation of grinding processes. CIRP Annals, 1992, Vol. 41, No. 2, pp. 677-688. https://doi.org/10.1016/S00078506(07)63254-5

[UHU 2012] UHU GmbH \& Co. KG. UHU PLUS ENDFEST 300. Technisches Merkblatt. 2012

[Wang 1995a] Wang, D. H. et al. Orthogonal cutting mechanisms of graphite/epoxy composite. Part I: unidirectional laminate. International Journal of Machine Tools and Manufacture 1995, Vol. 35, No. 12, pp. 1623-1638. https://doi.org/10.1016/0890-6955(95)00014-O
[Wang 1995b] Wang, D. H. et al. Orthogonal cutting mechanisms of graphite/epoxy composite. Part II: multidirectional laminate. International Journal of Machine Tools and Manufacture, 1995, Vol. 35, No. 12, pp. 1639-1648. https://doi.org/10.1016/0890-6955(95)00015-P

[Wang 2016a] Wang, $\mathrm{H}$. et al. Evaluation of cutting force and cutting temperature in milling carbon fiber-reinforced polymer composites. The International Journal of Advanced Manufacturing Technology, 2016, Vol. 82, pp. 1517-1525. https://doi.org/10.1007/s00170-015-7479-2

[Wang 2016b] Wang, $\mathrm{H}$. et al. The effect of cutting temperature in milling of carbon fiber reinforced polymer composites. Composites Part A: Applied Science and Manufacturing, 2016, Vol. 91, pp. 380-387. https://doi.org/10.1016/j.compositesa.2016.10.025

[Yashiro 2013] Yashiro, T. et al. Temperature measurement of cutting tool and machined surface layer in milling of CFRP. International Journal of Machine Tools and Manufacture, 2013, Vol. 70, pp. 63-69. https://doi.org/10.1016/j.ijmachtools.2013.03.009 